\title{
Un mes de desempeño legislativo: las sombras del pasado
}

El 1 de mayo se instaló la nueva asamblea legislativa. A partir de esa fecha hasta este momento, ha transcurrido casi un mes, tiempo ciertamente insuficiente para efectuar una evaluación a fondo de su desempeño y las perspectivas a las que podría estar apuntando. Con todo, mayo ha sido escenario de una serie de "arreglos" políticos que no pueden ser pasados por alto, especialmente porque traen a la memoria recuerdos no tan gratos de la anterior legislatura. En efecto, ARENA y el FMLN, contra todos los pronósticos que se hicieron antes y durante las elecciones del 16 de marzo, han logrado ponerse de acuerdo, con relativa facilidad, en la elección de la junta directiva de la asamblea legislativa y la conformación de las principales comisiones de trabajo que operan dentro de ésta. La sorpresa es mayor en cuanto a que el comportamiento de ARENA, en la pasada campaña electoral, dejó entrever un ánimo francamente confrontativo con todo lo que pudiera provenir de su principal rival político. La última posibilidad barajada, en ese entonces, fue la de una alianza entre ambas fuerzas políticas; sin embargo, esa posibilidad - plasmada en acuerdos concretoses la que ha pasado al primer plano del debate parlamentario, en el cual los partidos que presuntamente apoyarían al FMLN se han mostrado recelosos de la facilidad con la que parecen convivir quienes, al menos teóricamente, son portavoces de proyectos políticos contrapuestos.

No se puede dejar de señalar que, por la correlación de fuerzas existentes en su seno, la asamblea legislativa recién electa ha despertado muchas expectativas no sólo en los sectores mayoritarios del país, sino también en los sectores académicos e intelectuales. Mientras que para los primeros el control de importantes alcaldías por el FMLN, así como sus 27 diputados, ha dado pie a las esperanzas más variadas, para los segundos -entre quienes se encuentran los críticos más acervos tanto de la anterior legislatura como del gobierno del presidente Armando Calderón Sol- con los cambios políticos surgidos el 16 de marzo se ha abierto una posibilidad para que la incompetencia, la corrupción y los lastres autoritarios puedan ser superados.

Indudablemente, un trasfondo importante de las expectativas, suscitadas por los cambios surgidos a raíz de las pasadas elecciones, es el pésimo desempeño de la anterior asamblea legislativa, la cual —dada la preponderancia de ARENA, su habilidad para la compra de votos, el servilismo mostrado por los partidos de Conciliación Nacional y Demócrata, y la poca claridad del FMLNni de lejos pudo desempeñar la función que le compete al parlamento en el proceso de transición democrática; es decir, convertirse en correa de trasmisión entre las demandas de la sociedad civil y la capacidad institucional-estatal para responder a éstas.

Conviene recordar que, en los días previos a la terminación de sus funciones, la gran mayoría de los diputados salientes se dedicó a autoalabar su trabajo, incluso, hubo diputados reelectos que insistieron en lo mucho que trabajaron por el bien del país en el anterior período. Pero, desde el punto de vista crítico, esas alabanzas y autoalabanzas no fueron más que un mero ejercicio de demago- 
gia barata, cuyo colejo con la realidad las puso rápidamente en evidencia. Es pertinente traer a cuenta cómo inició y cómo concluyó su trabajo la legislatura anterior: lo inició con una maniobra, orquestada por el partido de ARENA, la Expresión Renovadora del Pueblo y la Resistencia Nacional, para tomar el control de la directiva de la asamblea legislativa; y lo terminó con un debate risible y ridículo sobre la despenalización de algunos casos de aborto.

En ambas situaciones, lo característico fue la propensión de los legisladores al espectáculo más burdo: en el primero de ellos, Joaquín Villalobos y los suyos haciendo alarde de una audacia rayana en el oportunismo más descarado; en el segundo, los diputados de ARENA rasgándose las vestiduras como defensores de la vida y como promotores de los valores humanos más queridos. En ambas situaciones, por supuesto, el gran ausente fue el bien común de los salvadoreños, que no tiene nada que ver ni con el oportunismo de lo que después sería el Partido Demócrata, ni con el "compromiso" con la vida proclamado por quienes la han despreciado en incontables oportunidades, valiéndose de la prepotencia, la matonería y el terrorismo. Para ganar prensa, tanto el oportunismo de unos como el "sí a la vida" de los otros necesitaban de un show que les sirviera de plataforma; con el espectáculo de los primeros se inició el trabajo legislativo que se cerró con el de los segundos.

Entre los actos, por si no bastara, los anteriores legisladores pasaron una y otra vez por encima del bien común y de los intereses generales. Así, oportunistas y "defensores de la vida" salieron nuevamente a escena, primero para firmar el Pacto de San Andrés; y, segundo, para aprobar un incremento al Impuesto al Valor Agregado (IVA). El espectáculo, ciertamente, no podía faltar, sobre todo para el primero de los acontecimientos señalados: con las ruinas de San Andrés como trasfondo, el Partido Demócrata decidió apostar lo que todavía le quedaba de credibilidad a favor del gobierno y del partido ARENA; mientras que estos últimos, hábilmente, jugaron a envolver a los autoproclamados socialdemócratas en un proyecto que sólo favorecía a sus intereses. Como resultado de ello, el IVA fue incrementado, los sectores populares resin- tieron la presión sobre sus bolsillos, y ARENA y el gobierno se salieron con la suya. El Partido Demócrala, por su parte, tuvo que reconocer que estos últimos sólo le prestarían atención cuando su ayuda fuera necesaria, y que nunca llegaría a ser el aliado estratégico del partido de derecha, por más que renunciara al comunismo, al marxismo o al estalinismo.

Después de la puesta en escena el Pacto de San Andrés, vinieron la Ley de emergencia contra la delincuencia y la aprobación (sujeta a ratificación) de la pena de muerte para los delitos de homicidio, violación y secuestro. Ambas iniciativas contaron con el patrocinio de ARENA, que no se detuvo ante nada con tal de demostrar a la sociedad en manos de quién estaba el poder de decidir sobre sus destinos. Además, el partido de gobiemo no sólo hizo un esfuerzo supremo para sumar a su favor la posición de partidos como el de Conciliación Nacional y Demócrata Cristiano, sino que involucró a sectores sociales importantes cuyo clamor por la ola delincuencial le sirvió de respaldo. De este modo, se generó un clima de opinión en favor de la ley contra la delincuencia - una ley, por cierto, muy discutible-, y de la aplicación de la pena de muerte como medida idónea para combatir la criminalidad.

ARENA, el gobierno y los sectores sociales que clamaban por una solución drástica al problema de la delincuencia se dieron la mano; por su parte, los medios de comunicación sumaron su voz a este coro que clamaba por la coerción estatal. Las voces críticas, las voces que apelaban a la razón, o bien fueron silenciadas o, peor aún, fueron presentadas como aliadas de los delincuentes.

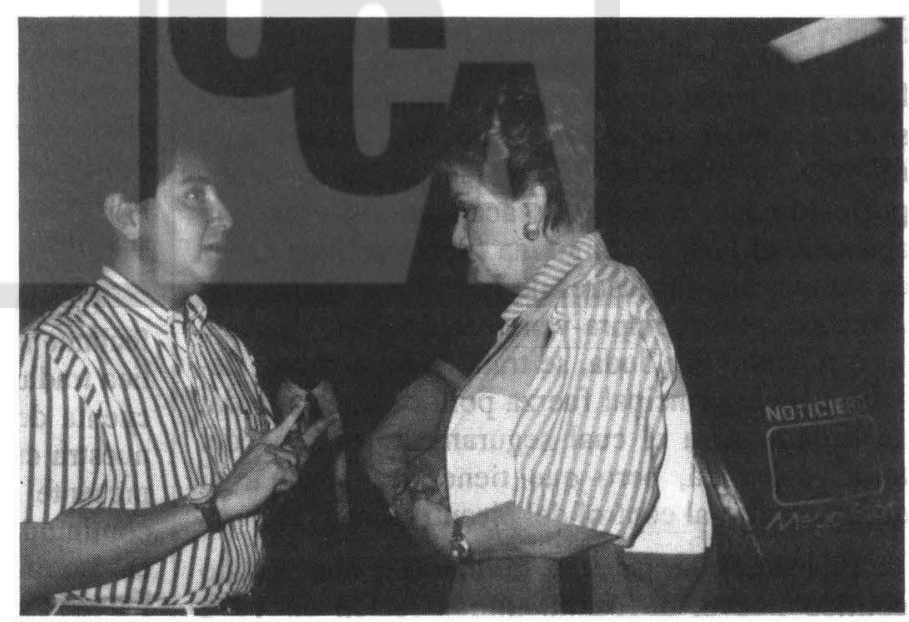


Una oleada neoconservadora, alentada por el gobierno y ARENA, impregnó el debate público. Desde la asamblea legislativa, que debía ser el espacio donde la racionalidad argumentativa tenía que prevalecer sobre cualquier interés particular o de grupo, se propagó una visión maniqueísta de la realidad, es decir, una visión en la que los buenos eran quienes aceptaban las decisiones oficiales, y los malos eran quienes las cuestionaban o hacian llamados a la racionalidad.

La peor herencia de la anterior legislatura fue, pues, la resistencia al debate público que se generó desde ella. Ciertamente, hubo mucho espectáculo; pero tras el mismo fueron los intereses y la cosmovisión de ARENA los que se impusieron. Los demás partidos fueron, por acción u omisión, piezas del juego diseñado por ARENA. Al tocar el tema de la anterior asamblea legislativa no pueden pasar desapercibidos los males que dejaron al país la prepotencia arenera, el oportunismo de los socialdemócratas y la pasividad de una izquierda de la que cabía esperar más de lo que efectivamente hizo. ARENA quizás haya cambiado -o está cambiando-, pero no existe una seguridad absoluta de que sus cambios lo lleven a dejar atrás sus pretensiones autoritarias, sus ansias de poder total y sus prácticas de compra-venta de favores políticos. No se trata de ser hipercríticos o paranoicos con el partido de derecha, pero tampoco se trata de ser ingenuos y creer que estamos ante un partido comprometido totalmente con las reglas y valores de la democracia. Este compromiso fue desmentido en el anterior período legislativo; es de esperar que el actual se convierta en una oportunidad para que ARENA haga algo distinto de lo que hizo en el pasado.

A priori, los resultados del 16 de marzo han hecho creer que con la nueva asamblea legislativa se va a romper con esa herencia. Muchos salvadoreños -entre quienes se encuentran trabajadores, profesionales, mujeres y académicos- le han apostado al FMLN como una fuerza política capaz de romper con los lastres de la política tradicional: compadrazgos, compra-venta de favores, chantaje y corrupción. Sin duda, se trata de un enorme desafío para la principal fuerza política de izquierda; un desafío para el cual seguramente no está del todo preparada, pero que tiene que afrontar si quiere aspirar al control del ejecutivo en 1999.

El FMLN, no hay que olvidarlo, es un partido político nuevo, cuyos miembros recién en 1992 comenzaron a entrenarse en el juego democrático electoral. Exigirles una renovación de la práctica política puede resultar una tarea demasiado gigantesca dada su inexperiencia en un terreno en el que apenas acaban de incursionar. Pero eso no es lo peor, sino el que nuestra práctica política ha caído presa de una serie de vicios que se han vuelto connaturales en quienes se mueven y desenvuelven en los círculos políticos. Hacer política en El Salvador significa no buscar el bien común y el interés de los cuidadanos, sino el interés propio de los individuos y grupos que conforman la clase política. Por supuesto, esa búsqueda del propio interés tiene patrones, en cierto modo institucionalizados, de comportamiento político, los cuales constituyen una especie de "camisa de fuerza" para quienes incursionan en el juego político. ¿Cuáles son esos patrones? Son el oportunismo, la compra-venta de favores, las negociaciones y los pactos a escondidas, y el afán de protagonismo. Quien decide incursionar en la política se tiene que relacionar con el círculo vicioso a que da lugar la práctica cotidiana, en el mundo político, de las taras apuntadas. Romper con los "valores" más queridos de la clase política salvadoreña no es tan fácil, especialmente cuando a partir de éstos se pueden obtener beneficios materiales que de otro modo serían inaccesibles.

Muchos participan en la política para obtener los mejores ( $\mathrm{y}$ mayores) réditos posibles; a éstos, la corrupción y el servilismo no les causa ningún resquemor, sino todo lo contrario: se sienten a sus anchas siendo comuptos y serviles. Otros -quizás los menos- lo hacen porque tienen vocación de servicio; a ellos no sólo los asustan los vicios de la política, sino que intentan combatirlos. En este combate, la mayor parte de veces, el perdedor es el político honesto que o bien es expulsado de los ćŕrculos políticos - por no estar en la "jugada"o bien termina siendo cooptado por sus colegas de profesión, los cuales pronto le hacen un sitio entre sus filas.

La anterior asamblea legislativa se ajustó perfectamente a las exigencias planteadas por la politica tradicional y sus valores más queridos. Habida cuenta de la fuerza que tienen éstos y aquélla en nuestra cultura política, no puede dejar de hacerse presente el temor de que la nueva legislatura de continuidad a esa nefasta tradición de hacer política. Lo único que se tiene hasta ahora para alimentar ese temor es lo que muchos consideran un peli- 
groso acercamiento entre ARENA y el FMLN. No es que ambas fuerzas políticas deban polarizar sus posiciones y enfrentarse cada vez que sea posible, pero tampoco se trata de marginar -amparándose en la simple aritmética política- a los partidos de oposición y, de paso, todo lo que éstos puedan aportar al debate parlamentario.

En principio - y esto debería estar claro para todos-, no es condenable que el FMLN y ARENA logren acuerdos políticos, siempre y cuando el criterio que los rija sea la búsqueda del bien común de los salvadoreños. Pero, de ningún modo ambos partidos pueden abrogarse el derecho a interpretar y decidir sin consultar a nadie más lo que es mejor para el país. De aquí a creer que los intereses nacionales se identifican con un determinado partido (o con dos) sólo hay un paso. Y lo que sigue después es lo que ya todo el mundo conoce: lo único que importa es el partido y sus intereses, a los cuales tiene que subordinarse todo lo demás. Se tiene que luchar denodadamente para no caer en esta lógica perversa; es mucho más peligrosa en cuanto que está arraigada en lo más profundo de la cultura política salvadoreña. Es una sombra del pasado que puede empañar todo lo renovador que puedan aportar los nuevos actores políticos.

En un escenario en el que ARENA y el FMLN están demostrando, al menos inicialmente, que tienen facilidades para negociar, el resto de partidos con representación en la asamblea legislativa deben cuidarse de dos cosas igualmente peligrosas: ante todo, de la exclusión de los acuerdos parlamentarios, al menos ahí donde la simple sumatoria se lo permita a ARENA y al FMLN; y, en segundo lugar, de los prejuicios negativos acerca de lo que pueda significar el acercamiento de los dos partidos mayoritarios. Sobre este segundo aspecto, los partidos de centro derecha y de centro izquierda no tienen por qué estar siempre a la defensiva por lo que ARENA y el FMLN puedan hacer jun- tos; al contrario, anteponiendo los intereses nacionales a los intereses partidarios, deben evaluar ponderadamente si esos acuerdos benefician o no al país, y actuar en consecuencia. Sobre lo primero, una decisión acertada, para tener presencia parlamentaria, es la conformación de un bloque de centro que, coherentemente, sea capaz de realizar una labor crítica y propositiva en el seno de la asamblea legislativa. Aquí, como siempre, se tendría que tener presente el eterno afán de protagonismo de determinados dirigentes y partidos para quienes el poder es una tentación inocultable.

Para terminar con la herencia del pasado, la asamblea legislativa en su conjunto, y cada uno de los diputados que la integran, tienen que dar muestras palpables de su compromiso por el bien común de El Salvador. El posicionamiento de los partidos en el escenario legislativo, las negociaciones y los pactos deben ser sólo un medio para ese fin que es la construcción de una sociedad democrática. En la medida en que ese fin sea soslayado, la asamblea legislativa seguirá reproduciendo los vicios políticos del pasado y posponiendo - causando un grave daño al país - sus responsabilidades en la transición democrática. La anterior legislatura hizo gala de los peores vicios del quehacer político salvadoreño; contribuyó al descrédito de la política en un grado extremo, y sirvió de espacio para las medidas más absurdas y contraproducentes para la transición democrática. La actual asamblea legislativa y sus diputados más lúcidos y honestos deben cuidarse de no caer en la "jaula de hierro" a la que se ven expuestos todos los que entran a ese mundo en el que el poder es la suprema tentación. No dejarse tentar por la ambición, no sucumbir al chantaje, no endiosarse (ni idiotizarse) con el poder: esas son las únicas cortapisas que se pueden poner a las asechanzas del pasado.

Luis Armando González 